www.jmscr.igmpublication.org

Impact Factor 5.84

Index Copernicus Value: 83.27

ISSN (e)-2347-176x ISSN (p) 2455-0450

crossref DOI: _https://dx.doi.org/10.18535/jmscr/v5i8.154

Journal Of Medical Science And Clinical Research

\title{
Effectiveness of Noninvasive Positive Pressure Ventilation in the Management of Acute Respiratory Failure
}

\section{Authors \\ Gosavi Rakhi A. ${ }^{1^{*}}$, Papinwar Shrikant ${ }^{2}$, Mhaisekar Dilip G ${ }^{3}$, Kapse Vijaykumar $\mathbf{R}^{4}$ Fazlullah Hashmi Syed ${ }^{5}$, Luniya Anandkumar Babulal ${ }^{6}$}

${ }^{1}$ Assistant Professor, Department of Pulmonary Medicine, B. J. Medical College, Pune, Maharashtra, India

${ }^{2}$ Professor, Department of Pulmonary Medicine, Indian \& R, Warudi, Badnapur, Maharashtra, India

${ }^{3}$ Ex Professor, Department of Pulmonary Medicine, Dr. Shankarrao Chavhan Govt. Medical College,

Nanded, Maharashtra, India, 9923195511, dilipmhaisekar@rediffmail.com

${ }^{4}$ Associate Professor, Department of Pulmonary Medicine, Dr. Shankarrao Chavhan Govt. Medical College,

Nanded, Maharashtra, India, 9970054685, pravin1702@gmail.com

${ }^{5}$ Ex Assistant Professor, Department of Pulmonary Medicine, Dr. Shankarrao Chavhan Govt. Medical

College, Nanded, Maharashtra, India, 9975643365, fhasi55@gmail.com

${ }^{6}$ Assistant Professor, Department of Pulmonary Medicine, Smt. Kashibai Navale Medical College, Pune,

Maharashtra, India, 9860727314, anand.luniya16@gmail.com

*Corresponding Author

Dr Rakhi A. Gosavi

Assistant Professor, Department of Pulmonary Medicine, B. J. Medical College, Pune, Maharashtra, India Email:dr.rakhigosavi@gmail.com,Ph.No. - 9881825252

\section{ABSTRACT}

Background: Noninvasive positive pressure ventilation (NIPPV) is increasingly being used in the management of patients with acute respiratory failure (ARF). The application of NIPPV in the management of patients with ARF is not associated with a $100 \%$ success rate. In many patients, application of NIV is clearly non effective as it does not obtain adequate ventilation and eventually endotracheal intubation and invasive mechanical ventilation is required. Also, some patients will initially benefit from NIPPV, but will then deteriorate and require intubation. The study was conducted to assess the efficiency of NIPPV in patients with acute respiratory failure.

Material and Methods: In this prospective observational study, a total 110 adult patients of respiratory failure and impending respiratory failure due to various diseases (COPD, Bronchial asthma, Bronchiectasis, ARDS, Pneumonia, Pulmonary oedema, ILD) and Post extubation who satisfied all the inclusion criteria attending a tertiary care centre and admitted in intensive respiratory care unit (IRCU) were studied.

Results: Amongst the total 110 patients studied the most common clinical diagnosis included exacerbation of COPD $37(33.63 \%)$ with or without associated co-morbidities. NIPPV was effective in 88 (80\%) and non-effective in 22 (20\%). There was significant improvement with NIPPV in form of increase in $\mathrm{pH}$ and $\mathrm{PaO} 2$ and decrease in PaCO2 after NIPPV application, which also persisted after successful weaning. The patients who failed NIPPV had significantly high respiratory rate, low pH value, and high $\mathrm{PaCO} 2$ on admission.

Discussion: The study demonstrated that NIPPV is not only a feasible ventilatory modality but also a treatment that is associated with significant improvements in clinical and biochemical outcomes.

Keywords: Non-invasive positive pressure ventilation, Acute respiratory failure, efficacy, weaning. 


\section{INTRODUCTION}

Acute respiratory failure (ARF) is a common cause of illness and death in patients admitted to critical care unit (CCU). Patients can get into CCU because of respiratory failure secondary to pulmonary pathology like pneumonia, status asthmaticus, pulmonary oedema in many other patients respiratory failure is secondary to sepsis, cardiac failure or neurological disorders ${ }^{[1]}$.

Endotracheal intubation and mechanical ventilation can be a life-saving procedure in patients with acute respiratory failure. These patients can be ventilated either with positive or negative pressure, invasively or noninvasively. The use of invasive intubation may lead to infectious complications and injury to the airways ${ }^{[2,3]}$.

Noninvasive positive-pressure ventilation (NPPV) is an alternative method of providing ventilatory support using a noninvasive interface with the patient and, thus, circumvents the complications of IMV like ventilator-associated pneumonias (VAP), injury to airways, barotrauma, and postintubation laryngeal and tracheal stenosis, while retaining the benefits of positive pressure ventilation ${ }^{[4-6]}$.

In recent years NPPV has gained wide acceptance and is now used more frequently. It has been shown to be beneficial for a variety of clinical conditions. Previous studies have demonstrated the efficacy of NPPV in acute exacerbation of chronic obstructive pulmonary disease (COPD) ${ }^{[7,8]}$, acute cardiogenic pulmonary oedema ${ }^{[9,10]}$, hypoxaemic respiratory failure ${ }^{[11]}$ and as an adjunct to weaning patients ${ }^{[12,13]}$.

The present study was conducted with the need for NIPPV for acute respiratory failure patients and the effectiveness of NIPPV for preventing the need of invasive mechanical ventilation.

\section{MATERIAL AND METHODS}

In this prospective observational study, a total 110 adult patients of respiratory failure and impending respiratory failure due to various diseases (COPD, Bronchial asthma, Bronchiectasis, ARDS, Pneumonia, Pulmonary oedema, ILD) and Post extubation who satisfied all the inclusion criteria attending a tertiary care centre and admitted in intensive respiratory care unit (IRCU) were studied from January 2013 to August 2014 over a period of 18 months.

\section{Inclusion criteria}

- Age more than 13 years.

- Patients with acute and impending respiratory failure with normal conscious level with able to maintain airway and mild to moderate hypoxemia.

- Patients on invasive mechanical ventilator for different etiologies who met weaning criteria were extubated early and included in study for immediate application of NIPPV.

\section{Exclusion criteria}

- Age less than 13 years.

- Patients with altered consciousness and who were unable to control airway as NIPPV is contraindicated in those.

Relevant investigations (Complete blood count, Kidney and Liver function tests, ECG, CXR, Serum electrolytes, Arterial blood gas analysis, Microbiological investigations) were done in patients on mechanical ventilation in critical care unit.

\section{Criteria for Acute Respiratory Failure}

At least two of the following criteria should be present:

- Respiratory distress with dyspnoea

- Use of accessory muscles of respiration

- Abdominal paradox

- Respiratory rate $>25 / \mathrm{min}$

Acute exacerbation of Chronic Obstructive Pulmonary disease

- Fatigue, hypersomnolence, dyspnoea

- Oxygen saturation < $88 \%$ for $>10 \%$ of monitoring time despite $\mathrm{O}_{2}$ supplementation.

\section{Criteria for patients to put on non-invasive} ventilation

- Patient able to cooperate, can control airway and secretions, with adequate cough reflex, able to co-ordinate breathing 
with ventilator, haemodynamically stable, Blood $\mathrm{pH}>7.1$ and $\mathrm{PaCO}_{2}<92 \mathrm{mmHg}$, improvement in gas exchange, heart rate and respiratory rate within first two hours and normal functioning gastrointestinal tract.

All the patients included in the study were interviewed for demographic data and detail history of their illness. All selected patients were subjected to detail physical examination. NIVBIPAP (mode spontaneous-timed) was used in all patients.

The patients were simultaneously started on standard medical treatment and $\mathrm{SpO}_{2}$ and arterial blood gases measured and non-invasive ventilation initiated with monitoring of pulse rate, respiratory rate, blood pressure and pulse oximetry. Arterial blood gases were measured at 1 hour and 4 hour after initiation of the non-invasive ventilation therapy.

Patients were also instructed about the procedure in detail prior to the application of NIV and were also positioned in a proper way.

\section{Protocol used for initiation and titrate bilevel positive airway pressure ${ }^{[14]}$}

NIPPV was delivered to patients in bed at an angle of $>30^{\circ}$ and in all patients a full face mask was used as an interface for delivery of positive pressure. Selected ventilator-Philips/Res-Med. and Set mode: spontaneous-timed. Started the IPAP at $8 \mathrm{~cm} \mathrm{H} 2 \mathrm{O}$ and the EPAP at $4 \mathrm{~cm} \mathrm{H} 2 \mathrm{O}$. IPAP maximum time 0.15 to $0.25 \mathrm{sec}$ longer than the patient's actual inspiratory time was set. IPAP maximum time should not be set longer than 50\% of the respiratory cycle. Headgear applied avoiding excessive strap tension (one or two fingers under strap); encouraged patient to hold mask. Connected interface to ventilator tubing and turned on ventilator. Started with low pressures/volumes in spontaneously triggered mode with backup rate; pressure-limited: 8 to 12 cm $\mathrm{H}_{2} \mathrm{O}$ inspiratory; 3 to $5 \mathrm{~cm} \mathrm{H} 2 \mathrm{O}$ expiratory. volume-limited: $10 \mathrm{ml} / \mathrm{kg}$. Gradually increased inspiratory pressure with 1 to $2 \mathrm{~cm} \mathrm{H} 2 \mathrm{O}$ increments (10 to $20 \mathrm{~cm} \mathrm{H} 2 \mathrm{O}$ ) or tidal volume (10 to $15 \mathrm{ml} / \mathrm{kg}$ ) as tolerated to achieve alleviation of dyspnea, decreased respiratory rate, increased tidal volume (if being monitored), to provide more ventilator assistance and good patient-ventilator synchrony. Also increased EPAP in 1 to $2 \mathrm{~cm}$ $\mathrm{H}_{2} \mathrm{O}$ increments to improve oxygenation or to relieve upper airway obstruction. If poor synchronization occurred, checked for leaks or altered IPAP maximum time to improve synchronization. Supplemental oxygen was used if baseline saturation remains low $(\mathrm{SpO} 2<85 \%$ with finger pulse oximeter) with appropriate IPAP and EPAP settings. Readjusted straps as needed. IPAP or EPAP level was not increased beyond patient tolerance. Humidifier was added as indicated. In agitated patients mild sedation with intravenous lorazepam $0.5 \mathrm{mg}$ was used. Monitored blood gases (within 1 to $2 \mathrm{~h}$ and then as needed). Also patient is regularly evaluated clinically and investigated as per requirement. Bronchodilators and corticosteroids as nebulisers and antibiotic agents were given where clinically indicated.

Instituted alternative management plan if $\mathrm{PaCO} 2$ and $\mathrm{pH}$ have deteriorated after 1-2 hours of NIV on optimal settings. If no improvement, continued with NIV and reassess with repeat arterial blood gas analysis after 4-6 hours. If still no improvement in $\mathrm{PaCO} 2$ and $\mathrm{pH}$ by $4-6$ hours, alternative management plan was considered.

NIPPV failure was defined as the need for invasive mechanical ventilation (IMV) due to worsening of clinical features such as respiratory distress (tachypnea, tachycardia, increased work of breathing) hypotension, worsening of the level of consciousness, or laboratory evidence of worsening or persistent respiratory distress while on NIPPV.

Any deterioration of $\mathrm{pH}$ and increase $\mathrm{PaCO}_{2}$, worsening of mental status, intolerance to NIV (clinical and/or laboratory evidence of deterioration at any point during NIPPV intervention), such patients were proceeded to invasive ventilation within 4 hours of starting the therapy. 
Arterial blood gas analysis was done at the time of weaning and 6 hours after weaning were done. Once the patient improved clinically and corroborated by improvements in arterial blood gases, weaning was initiated. During the weaning phase, the IPAP was decreased in gradations of 2$3 \mathrm{~cm}$ until the IPAP was $7-10 \mathrm{~cm}$. The application was then switched over to intermittent use. The time of weaning, thus, was different for each patient.

NIPPV for weaning from invasive mechanical ventilation $^{[15]}$

If the patient of acute respiratory failure was intubated on the basis of clinical and laboratory deterioration the weaning criteria as following were evaluated:

- Improved underlying illness.

- Respiratory function -

- Respiratory rate $<35$ breaths/minute

- $\mathrm{FiO} 2<0.4, \mathrm{SaO} 2>90 \%$, PEEP < 10 $\mathrm{cmH} 2 \mathrm{O}$

- $\quad$ Tidal volume $>5 \mathrm{ml} / \mathrm{kg}$

- Vital capacity $>10 \mathrm{ml} / \mathrm{kg}$

- Minute volume $<10$ 1/min

- Gas exchange stability $(\mathrm{PaO} 2 \geq 60 \mathrm{~mm} \mathrm{Hg}$ with $\mathrm{SaO} 2 \geq 90 \%$ and $\mathrm{FiO} 2 \leq 40 \%$ ),

- Pulmonary mechanics stability (control of pulmonary edema, atelectasis, secretions, and bronchospasm).

- Absence of infection or fever.

- Cardiovascular stability (like hemoglobin $\geq 8 \mathrm{~g} / \mathrm{dl}$, no severe arrhythmia), optimal fluid balance and electrolyte replacement.

- Hemodynamic stability (absence of vasopressors or vasopressors in doses $\leq 5$ $\mu \mathrm{g} / \mathrm{kg} / \mathrm{min}$ )

- Neurologic stability (Glasgow coma scale $>10)$.

Prior to trial of weaning, there should be no residual neuromuscular blockade and sedation should be minimised so that cooperative and in a semi-recumbent position.

\section{Weaning Failure}

Weaning failure is defined as the failure to pass a spontaneous-breathing trial or the need to reintubation within 48 hours following extubation. For studying NIPPV as a weaning method - 1) included adults, with respiratory failure, invasively ventilated for at least $24 \mathrm{hr}$; 2) Immediate application of NPPV (BiPAP) after extubation. Patients with contraindications to NPPV were excluded. Patients needing intubation after extubation i.e. weaning failure or extubation failure patients were applied with NIPPV- BiPAP. In present study effectiveness of NIV means improvement in ABG parameter and noneffectiveness means worsening of ABG parameter. All the study patients were followed up until discharge. Patients taking discharge against medical advice were excluded.

Collected data with the help of proforma was entered in MS EXCEL 2007 spread sheet and then analysed.

\section{RESULTS}

Amongst the total 110 patients in study, there were $68(61.81 \%)$ male and $42(38.18 \%)$ female patients with the mean age of study population $49.40( \pm 9.89)$ years. Majority $48(43.63 \%)$ of the patients were in the age group of 55-74 years. The commonest indication of NIPPV in present study was COPD in 37 (33.63\%) cases followed by post extubation 30 (27.27\%), asthma 14 (12.72\%), ARDS $9(8.18 \%)$ and pneumonia $10(9.09 \%)$ (Table 1).

Table 1: Indications for NIPPV

\begin{tabular}{|l|c|}
\hline Diseases & No. of patients $(\%)$ \\
\hline COPD & $37(33.63 \%)$ \\
\hline Post-extubation & $30(27.27 \%)$ \\
\hline Asthma & $14(12.72 \%)$ \\
\hline Pneumonia & $10(9.09 \%)$ \\
\hline ARDS & $09(8.18 \%)$ \\
\hline Pulmonary edema & $06(5.45 \%)$ \\
\hline Bronchiectasis & $03(2.72 \%)$ \\
\hline ILD & $01(0.90 \%)$ \\
\hline Total & $110(100 \%)$ \\
\hline
\end{tabular}

Out of 110 patients taken on NIPPV, 18 (16.36\%) patients required ventilation for $<12 \mathrm{hrs}, 30$ $(27.27 \%)$ patients required for $12-24 \mathrm{hrs}, 44$ (40\%) patients required for $24-48 \mathrm{hrs}$. Prolonged mechanical ventilation ( $>48 \mathrm{hrs}$ ) were required in $18(16.36 \%)$ patients. 
Table 2: Duration of NIPPV in Different Diseases

\begin{tabular}{|c|c|c|c|c|c|}
\hline Diseases & $<12 \mathrm{hrs}$ & $12-24 \mathrm{hrs}$ & $24-48$ hrs & $>48 \mathrm{hrs}$ & Total \\
\hline COPD & 0 & 4 & 24 & 9 & 37 \\
\hline Asthma & 2 & 10 & 2 & 0 & 14 \\
\hline Bronchiectasis & 1 & 2 & 0 & 0 & 3 \\
\hline ARDS & 0 & 1 & 1 & 7 & 9 \\
\hline Pneumonia & 1 & 5 & 4 & 0 & 10 \\
\hline Pulmonary Edema & 0 & 1 & 5 & 0 & 6 \\
\hline ILD & 0 & 0 & 0 & 1 & 1 \\
\hline Post Extubation & 14 & 7 & 8 & 1 & 30 \\
\hline Total & 18 & 30 & 44 & 18 & 110 \\
\hline Percentage $(\%)$ & $16.36 \%$ & $27.27 \%$ & $40 \%$ & $16.36 \%$ & $100 \%$ \\
\hline
\end{tabular}

NIPPV was effective in $88(80 \%)$ but found non effective in $22(20 \%)$.

Table 3: Outcome Of NIPPV in Present Study

\begin{tabular}{|l|c|c|}
\hline Outcome & Number of patients & Percentage (\%) \\
\hline Effective & 88 & $80 \%$ \\
\hline Non Effective & 22 & $20 \%$ \\
\hline Total & 110 & $100 \%$ \\
\hline
\end{tabular}

Amongst the total 110 patients, $22(20 \%)$ patients required invasive ventilation, out of them 6 (16.21\%) of Chronic Obstructive Pulmonary Disease (COPD), 1 (7.14\%) of asthma, 5 (55.55\%) of ARDS, 2 (20\%) of pneumonia, 2 $(33.33 \%)$ of pulmonary edema, 6 (20\%) of post extubation patients. Out of 3 patients of bronchiectasis and 1 patient of ILD no one required invasive ventilation.

Of the $22(20 \%)$ patients required invasive ventilator, $12(54.54 \%)$ were due to worsening of ABG parameter, $8(36.36 \%)$ were due to altered consciousness, and $2(9.09 \%)$ were due to increase respiratory secretions.

Table 4: Disease-wise distribution of patients and their outcome on NIPPV

\begin{tabular}{|l|c|c|}
\hline Diseases & $\begin{array}{c}\text { Total cases on } \\
\text { NIPPV }\end{array}$ & $\begin{array}{c}\text { No. of cases Required } \\
\text { Invasive Ventilation }\end{array}$ \\
\hline COPD & 37 & $06(16.21 \%)$ \\
\hline Asthma & 14 & $01(7.14 \%)$ \\
\hline Bronchiectasis & 03 & $00(0 \%)$ \\
\hline ARDS & 09 & $05(55.55 \%)$ \\
\hline Pneumonia & 10 & $02(20 \%)$ \\
\hline Pulmonary edema & 06 & $02(33.33 \%)$ \\
\hline ILD & 01 & $00(0 \%)$ \\
\hline Post-extubation & 30 & $06(20 \%)$ \\
\hline Others & 00 & $00(0 \%)$ \\
\hline Total & 110 & $22(20 \%)$ \\
\hline
\end{tabular}

A total of $39(81.25 \%)$ of hypercapnic respiratory failure patients, 27 (75\%) of hypoxic respiratory failure patients and $22(84.61 \%)$ of mixed respiratory failure patients weaned off successfully.
Noninvasive Ventilator was not effective 4 (20\%) were in the age group of 14-34 years, 5 (16.66\%) in $35-54$ years, $11(22.91 \%)$ in $55-74$ years and 2 $(100 \%)$ were in the age group of $>75$ years.

In 30 patients NIPPV used for weaning after early extubation $6(20 \%)$ of them required reintubation, total 19 patients were of poisoning out of them 3 $(15.7 \%)$ required reintubation, 4 of COPD 2 (50\%) required reintubation, 2 patient of ARDS was given NIPPV support after early extubation 1 $(50 \%)$ required reintubation.

Table 5: NIPPV used for weaning after early extubation in different diseases

\begin{tabular}{|l|c|c|}
\hline Diseases & $\begin{array}{c}\text { No. of } \\
\text { patients used } \\
\text { NIPPV }\end{array}$ & $\begin{array}{c}\text { No. of patients Required } \\
\text { reintubation }\end{array}$ \\
\hline Poisoning & 19 & $3(15.7 \%)$ \\
\hline COPD & 4 & $2(50 \%)$ \\
\hline Pneumonia & 2 & $0(0 \%)$ \\
\hline Snake bite & 1 & $0(0 \%)$ \\
\hline Meningoencephalitis & 1 & $0(0 \%)$ \\
\hline ARDS & 2 & $1(50 \%)$ \\
\hline Cerebrovascular accident & 1 & $0(0 \%)$ \\
\hline Total & 30 & $6(20 \%)$ \\
\hline
\end{tabular}

\section{DISCUSSION}

The present study was prospective observational study conducted to determine the indications of non-invasive mechanical ventilation in patients of respiratory failure admitted in critical care unit due to various conditions. These patients were evaluated on the basis of clinical parameters and oxygen saturation on pulse oximetry. Duration of mechanical ventilator stay, complications of mechanical ventilation, ABG parameters, clinical outcome according to different underlying conditions were studied.

In present study, mean age among the study population was $49.40( \pm 9.89)$ years, Similarly, in the studies by George et al ${ }^{[16]}$ and Lt. Col. Rai et 
al ${ }^{[17]}$, the average age of patients enrolled was $>50$ years.

The present study has a male preponderance (68/110) of $61.8 \%$; the study of Agrawal et al ${ }^{[18]}$ and Vanani et al ${ }^{[19]}$, had a male preponderance of $63 \%$ and $86 \%$ respectively.

The common indication for initiation of NIPPV was COPD $37(33.63 \%)$ followed by Postextubation $30(27.27 \%)$ in present study. Other indications were Asthma 14 (12.72\%), Bronchiectasis $3(2.72 \%)$, ARDS 9 (8.18\%), Pneumonia 10 (9.09\%), Pulmonary edema 6 (5.45\%), and ILD 1 $(0.90 \%)$. Chawla et al ${ }^{[20]}$, Rai et al ${ }^{[17]}$ and Agrawal et al ${ }^{[18]}$ found that $71.4 \%, 64.4 \%$ and $38.1 \%$ patients had COPD respectively.

In this study, the mean duration of mechanical ventilation was $29.28( \pm 19.73)$ hours. In a study by Meduri et al ${ }^{[6]}$ mean duration of face mask mechanical ventilation was $25 \mathrm{~h}$. Lt Col SP Rai et al ${ }^{[17]}$ used NIPPV for 5.4 days (range 2 to 15 days) prior to discharge. In some other studies NIV was administered for only a relatively short period (mean $7.6 \mathrm{~h}$ and $6 \mathrm{~h}$ daily) or at very modest levels for a longer period. It appears that even short periods of NIV are usually sufficient to break the vicious circle produced by acidosis while other therapies take effect upon the precipitating cause ${ }^{[21] .}$

NIPPV were effective in $88(80 \%)$ and noneffective in $22(20 \%)$ patients in this study. Similar to study done by George et al ${ }^{[16]}$ with success rate of NIPPV was $85 \%$, and Meduri et al ${ }^{[22]}$ with $80 \%$ success rate.

The failure rates of NIPPV can range from $5 \%$ to $50 \%$ in different studies depending on the etiology and severity of ARF. The success rate of NIPPV was $87.5 \%$ for ARF due to COPD and $61.5 \%$ for ARF due to other causes which are similar to reintubation rates described elsewhere both from India and the European-American countries ${ }^{[18]}$.

In the present study, amongst the total 110 patients $22(20 \%)$ patients required invasive ventilation, out of them $6(16.21 \%)$ of COPD, 1 (7.14\%) of Asthma, 5 (55.55\%) of ARDS, 2 (20\%) of Pneumonia, 2 (33.33\%) of Pulmonary edema, 6 (20\%) of post extubation patients. Out of 3 patients of Bronchiectasis and 1 patient of ILD no one required invasive ventilation. Phua $J$ et al ${ }^{\text {[23] }}$ reported that risk of NIV failure was lower in COPD than in other condition (19\% vs 47\%) respectively.

In a study done by Schettino et al ${ }^{[24]}$, intubation rate was $18 \%, 24 \%, 38 \%, 40 \%$, and $60 \%$, respectively, for patients with cardiogenic pulmonary edema, acute exacerbation of COPD, acute hypercapnic respiratory failure, post extubation respiratory failure patients and acute hypoxemic respiratory failure.

In a study by Antonelli et $\mathrm{al}^{[25]}$, of the eligible 354 patients NIV failed in 30\% (108/354) patients. The highest intubation rate was found in patients with ARDS (51\%) and community acquired pneumonia (50\%). The lowest intubation rate was observed in patients with cardiogenic pulmonary edema (10\%) and pulmonary contusion (18\%).

In the present study, amongst the total 110 patients $22(20 \%)$ patients required invasive ventilator, out of them $12(54.54 \%)$ were due to worsening of ABG parameter, 8 (36.36\%) were due to altered consciousness, and $2(9.09 \%)$ were due to increase respiratory secretions. Phua et $\mathrm{al}^{[23]}$ found that NIV was more effective in preventing endotracheal intubation in hypercapnic ARF due to COPD than non-COPD conditions. In the study by Yoshida et al ${ }^{[26]}$ studied a total of 47 patients with ALI who received NIV, and 33 patients $(70 \%)$ successfully avoided endotracheal intubation.

In the present study, $39(81.25 \%)$ of Hypercapnic respiratory failure patients weaned off successfully, 27 (75\%) of Hypoxic respiratory failure patients weaned off successfully and 22 $(84.61 \%)$ of Mixed respiratory failure patients weaned off successfully. Cheung et al ${ }^{[27]}$ found that for hypoxaemic respiratory failure and hypercapnic respiratory failure groups, improvements in gas exchange were seen in approximately $71 \%$ of these patients, endotracheal intubation was not needed for $82 \%$. Wysocki et $\mathrm{al}^{[28]}$ found that intermittent positive support 
ventilation delivered from a ventilator through a face mask (NIPSV) reduced the need for endotracheal intubation with a success rate of $47 \%$ in patients presenting with acute respiratory failure from various etiologies.

In present study, NIV was not effective 11 (22.91\%) patients of 55-74 years. Patients with worsening of ABG parameter 12 (54.54\%) followed by a poor level of consciousness 8 $(36.36 \%)$ were associated with a poor response to NIPPV, ultimately requiring intubation. Mean $\mathrm{pH}$ value on admission was lower in patients who failed NIPPV i.e. (7.29) compared to that in NIPPV successful group (7.35). Thus patients with $\mathrm{pH}$ between 7.3-7.45 fared well on NIPPV and were successfully weaned. This could perhaps set a lower limit of $\mathrm{pH}$ as an indication for NIPPV. NIPPV was associated with improvements in $\mathrm{pH}$ from (7.35) to (7.37) after application. This improvement continued up to the time of weaning and was maintained post-weaning. Mean $\mathrm{PaCO} 2$ value at admission was higher in patients of COPD who failed NIPPV $(66.87 \mathrm{~mm} \mathrm{Hg})$ compared with NIPPV responders $(55.69 \mathrm{~mm} \mathrm{Hg}$ ) and, thus, could also possibly be used to predict response to NIPPV. There was improvement in the mean $\mathrm{PaCO} 2$ levels after application of NIPPV from $55.69 \mathrm{~mm} \mathrm{Hg}$ to $49.45 \mathrm{~mm} \mathrm{Hg}$. This improvement continued up to weaning and was maintained post-weaning from IPPV. There was improvement in the mean $\mathrm{PaO} 2$ levels from 71.62 $\mathrm{mm} \mathrm{Hg}$ to $82.29 \mathrm{~mm} \mathrm{Hg}$ This improvement continued up to weaning and post-weaning. In a study done by Antonelli et al ${ }^{[25]}$, of the eligible 354 patients NIV failed in 30\% (108/354) patients. Multivariate analysis identified age $>40$ years (OR 1.72, 95\% CI 0.92-3.23), the presence of ARDS or community acquired pneumonia as independent factors associated with NIV failure.

Amongst the total 110 patients on NIV, in 30 patients NIPPV used for weaning after early extubation $6(20 \%)$ of them required reintubation, total 19 patients were of Poisoning out of them 3 $(15.7 \%)$ required reintubation, 4 of COPD 2 $(50 \%)$ required reintubation, 2 patient of ARDS was given NIPPV support after early extubation 1 $(50 \%)$ required reintubation. Girault et al [29] found that it is possible to use NIV immediately as an early extubation and weaning technique in intubated (ACRF) acute-on-chronic respiratory failure patients who are difficult to wean, 13 of 17 $(76.5 \%)$ in the NIV group were successfully weaned and extubated.

The findings of this prospective observational study confirm other previous reports on the effectiveness of NIV in managing patients with respiratory failure. The study demonstrated that NIPPV is not only a feasible ventilatory modality but also a treatment that is associated with significant improvements in clinical and biochemical outcomes. It has not been found useful in the patients with significantly high respiratory rate, low $\mathrm{pH}$ value, and high $\mathrm{PaCO} 2$ on admission. NIPPV represents a significant advance in the treatment of selected patients with acute respiratory failure.

CONFLICT OF INTEREST: None declared. SOURCE OF FUNDING: Nil.

ACKNOWLEDMENT: We would like to thank the patients, nursing and medical staffs of the study hospital for their cooperation for the success of the study.

\section{Contribution of authors:}

${ }^{1}$ Acquisition, analysis and interpretation of data

${ }^{3}$ Concept \& Final approval for the version

$2,4,5,6$ Design, Drafting and revising the manuscript

\section{REFERENCES}

1. Dean E, Schraufnagel. Breathing in America: Diseases, Progress, and Hope. USA: American Thoracic Society 2010.

2. Pingleton SK. Complications of acute respiratory failure. Am Rev Respir Dis 1988;137:1463-93.

3. Stauffer JL, Olson DE, Petty TL. Complications and consequences of endotracheal intubation and tracheotomy: A prospective study of 150 critically ill adult patients. Am J Med 1981;70:65-76. 
4. Meduri GU, Conoscenti CC, Menashe P, Nair S. Noninvasive face mask ventilation in patients with acute respiratory failure. Chest 1989;95:865-70.

5. Brochard L, Isabey D, Piquet J, Amaro P, Mancebo J, Messadi AA, et al. Reversal of acute exacerbations of chronic obstructive lung disease by inspiratory assistance with a face mask. $\mathrm{N}$ Engl $\mathrm{J}$ Med 1990;323:1523-30.

6. Meduri GU, Abou-Shala N, Fox RC, Jones $\mathrm{CB}$, Leeper KV, Wunderink RG. Noninvasive face mask mechanical ventilation in patients with acute hypercapnic respiratory failure. Chest 1991;100:445-54.

7. Carrera M, Marín JM, Antón A, et al. A controlled trial of noninvasive ventilation for chronic obstructive pulmonary disease exacerbations. J Crit Care 2009; 24: 473.e7-e14.

8. Khilnani GC, Saikia N, Sharma SK, Pande JN, Malhotra OP. Efficacy of noninvasive pressure ventilation for the management of COPD with acute or acute on chronic respiratory failure: A randomized controlled trial. Am J Respir Crit Care 2002;165:A387.

9. Potts JM. Noninvasive positive pressure ventilation: effect on mortality in acute cardiogenic pulmonary edema: a pragmatic meta-analysis. Pol Arch Med Wewn 2009; 119: 349-353.

10. Gray A, Goodacre S, Newby DE, et al. Noninvasive ventilation in acute cardiogenic pulmonary edema. N Engl J Med 2008; 359: 142-151.

11. Ferrer M, Esquinas A, Leon $M$, et al. Noninvasive ventilation in severe hypoxemic respiratory failure: a randomized clinical trial. Am J Respir Crit Care Med 2003; 168: 1438-1444.

12. Trevisan CE, Vieira SR. Research Group in Mechanical Ventilation Weaning. Noninvasive mechanical ventilation may be useful in treating patients who fail weaning from invasive mechanical ventilation: a randomized clinical trial. Crit Care 2008; 12: R51.

13. Ferrer M, Esquinas A, Arancibia F, et al. Noninvasive ventilation during persistent weaning failure: a randomized controlled trial. Am J Respir Crit Care Med 2003; 168: 70-76.

14. Mehta S, Hill NS. Noninvasive ventilation. Am J Respir Crit Care Med 2001;163:540-577.

15. Boles JM, Bion J, Connors A, et al. Weaning from mechanical ventilation. Eur Respir J 2007; 29:1033-1056.

16. George IA, George J, John P, Peter JV, Christopher S. An evaluation of the role of noninvasive positive pressure ventilation in the management of acute respiratory failure in a developing country. Indian J Med Sci 2007;61:495-504.

17. Lt Col S P Rai, Brig B N Panda, Lt Col K K Upadhyay, Noninvasive Positive Pressure Ventilation in Patients with Acute Respiratory Failure, MJAFI 2004;60: 224226.

18. Agarwal R, Handa A, Aggarwal AN, Gupta D, Behera D. Outcomes of Noninvasive Ventilation in Acute Hypoxemic Respiratory Failure in a Respiratory Intensive Care Unit in North India, Respiratory Care 2009;54:12.

19. Vanani V, Patel M. A study of patients with type 2 respiratory failure put on noninvasive positive ventilation, Ann Trop Med Public Health 2013;6:369-77.

20. Chawla R, Sidhu US, Kumar V, Nagarkar S, Brochard L. Noninvasive ventilation: A survey of practice patterns of its use in India, Indian J Crit Care Med 2008;12: 4.

21. Elliott MW. Non-invasive ventilation for acute respiratory disease. British Medical Bulletin 2004; 72: 83-97.

22. Meduri GU, Turner RE, Abou-Shala N, Wunderink R, Tolley E. Noninvasive 
positive pressure ventilation via face mask. Chest 1996;109: 179-193.

23. Phua J, Kong K, Lee KH, Shen L, Lim TK .Noninvasive ventilation in hypercapnic acute respiratory failure due to chronic obstructive pulmonary disease vs. other conditions: effectiveness and predictors of failure. Intensive Care Med 2005;31(4):533-9.

24. Schettino, Guilherme, Altobelli, Neila BA, Kacmarek and Robert M. Noninvasive positive-pressure ventilation in acute respiratory failure outside clinical trials: Experience at the Massachusetts General Hospital; (C) 2008 by the Society of Critical Care Medicine and Lippincott Williams \& Wilkins.

25. Antonelli M, Conti G, Rocco M, et al. Noninvasive positive pressure ventilation vs. conventional oxygen supplementation in hypoxemic patients undergoing diagnostic bronchoscopy. Chest 2002;121:1149-54.

26. Yoshida Y, Takeda S, Akada S, Hongo T, Tanaka K, Sakamoto A, Factors predicting successful noninvasive ventilation in acute lung injury. J Anesth. 2008;22(3):201-6.

27. Cheung MT, Yam LYC, Lau CW, Ching $\mathrm{CK}$, Lee $\mathrm{CH}$. Use of non-invasive positive-pressure ventilation for acute respiratory failure: prospective study, HKMJ Vol 6 No 4 December 2000.

28. Wysocki M, Antonelli M. Noninvasive mechanical ventilation in acute hypoxaemic respiratory failure, Eur Respir J 2001;18: 209-220.

29. Girault C, Daudenthun I, Chevron V, Tamion F, Leroy J, Bonmarchand G. Noninvasive ventilation as a systematic extubation and weaning technique in acute-on-chronic respiratory failure: a prospective, randomized controlled study. Am J Respir Crit Care Med 1999; 160:8692. 